39 | InterAção

\title{
A HEGEMONIA BRITÂNICA NO BRASIL DO SÉCULO XIX
}

\author{
Diego Marques Morlim Pereira1
}

\section{Resumo}

A questão da hegemonia no sistema internacional gera uma série de debates sobre sua posição como fator de estabilidade ou de instabilidade do sistema internacional, sobre custos e benefícios de se manter a hegemonia para os Estados e sobre a ascendência e o declínio de hegemons no sistema internacional durante a História. Tomando-se o século XIX como recorte temporal, a discussão sobre hegemonia no sistema internacional tem de abordar a Inglaterra como principal polo de poder mundial. Isto posto, nesse trabalho buscar-se-á discutir questões relacionadas à hegemonia no ambiente internacional, sob as lentes realista e marxista, assim como analisar o funcionamento da hegemonia britânica no Brasil do século XIX.

Palavras-chave: Século XIX; Hegemonia; Brasil; Realismo; Marxismo

\begin{abstract}
The issue of hegemony in the international system provides a series of debates about its role as a factor of international stability or instability, as well as about the costs and benefits of being a hegemon state and about the rise and fall of hegemons in the world system throughout history. While discussing hegemony in the international system the $19^{\text {th }}$ century, Great Britain shall be seen as the main world power of that era. This work looks for discussing issues related to hegemony in the international environment under the lenses of realist and Marxist theories of International Relations, as well as analyzing how the British hegemony affected Brazil in the $19^{\text {th }}$ century.
\end{abstract}

Keywords: 19th century; Hegemony; Brazil; Realism; Marxism

\footnotetext{
${ }^{1}$ Doutorando em Ciência Política pelo Instituto de Estudos Sociais e Políticos (IESP-UERJ); bolsista FAPERJ. Mestre em Relações Internacionais pela Pontifícia Universidade Católica de Minas Gerais (2014). Bacharel em Relações Internacionais pela Pontifícia Universidade Católica de Minas Gerais (2007).
} 
40 InterAção

A questão da hegemonia no sistema internacional gera uma série de debates sobre sua posição como fator de estabilidade ou de instabilidade do sistema internacional, sobre custos e benefícios de se manter a hegemonia para os Estados e sobre a ascendência e o declínio de hegemons no sistema internacional durante a História. Tomando-se o século XIX como recorte temporal, a discussão sobre hegemonia no sistema internacional tem de abordar a Inglaterra como principal polo de poder mundial. Isto posto, nesse trabalho buscar-se-á discutir questões relacionadas à hegemonia no ambiente internacional, sob as lentes realista e marxista, assim como analisar o funcionamento da hegemonia britânica no Brasil do século XIX.

\section{A HEGEMONIA SEGUNDO AS TEORIAS DAS RELAÇÕES INTERNACIONAIS: REALISMO E MARXISMO}

Realistas determinam que o sistema internacional é constituído por unidades, especificamente Estados soberanos, que interagem entre si dentro de uma estrutura, que consiste no arranjo entre as unidades. Em geral, poucos Estados encontram-se no topo da hierarquia de poder e, consequentemente, são capazes de moldar as interações entre os demais atores sob seus interesses. Enquanto o hegemon define a dinâmica do sistema internacional, os outros Estados possuem menor relevância no sistema, o que demonstra a desigualdade inerente no sistema internacional (WALTZ, 2002).

A distribuição de poder no sistema internacional define-se pela utilização pelos Estados de capacidades militares, políticas e econômicas para defender seus interesses. Entre essas capacidades, pode-se destacar "tamanho da população e do território, dotação de recursos, capacidade econômica, força 
41 InterAção

militar, estabilidade política e competência" (WALTZ, 2002, p.182). Devido ao fato de o poder ser relativo, para os realistas, pode-se afirmar que a ascensão ou o declínio de uma hegemonia se relaciona com o poderio dos demais Estados, ou seja, com o aumento ou o declínio do poder de seus inimigos (GILPIN, 1981).

A presença de uma potência hegemônica no sistema internacional pode ser considerada relevante para organizar e para assumir responsabilidade sobre o sistema. Essa hegemonia envolve benefícios, em geral econômicos e de prestígio, e custos relacionados aos recursos disponibilizados para a manutenção no posto de hegemon e para a governança do sistema internacional (GILPIN, 1981).

No fim do século XVIII a Inglaterra passou pela Revolução Industrial e passou a defender o livre comércio (Adam Smith, A riqueza das nações) em detrimento ao mercantilismo. Esse fato é importante para que se compreenda a posição britânica contrária aos ideais intervencionistas e recolonizadores da Santa Aliança e ao apoio que aquele país deu às independências na América Latina no primeiro quarto do século XIX.

No século XIX, a Inglaterra se configurava como potência comercial e industrial dominante e, por isso, colocou-se em posição de organizar e estabilizar o sistema internacional. O Conserto Europeu (1815), após as guerras napoleônicas, e a pax britânica que se seguiu a ele, são exemplos dessa hegemonia sistêmica da Inglaterra naquele período.

Os custos da governança do sistema internacional pautavam-se em intervenções esporádicas, como na Guerra da Criméia; em empréstimos a aliados; e em manter-se como hegemon em face de desafiantes como França, na primeira metade do século XIX, e Alemanha, na segunda metade daquele século. 
42 InterAção

Os benefícios, no entanto, pareceram superar os custos. A Inglaterra tornou-se a principal potência mundial, dominava o comércio internacional, administrava as finanças internacionais por intermédio do padrão ouro, garantia mercado consumidor para seus produtos, influenciava políticas internas, externas, regionais, etc. A influência inglesa no Brasil do século XIX foi marcante, especialmente em relação à política e à economia, questões que serão analisadas na próxima seção.

Os marxistas, por sua vez, fazem uma análise das relações internacionais que se vincula àquela dos realistas, especialmente no que diz respeito ao papel do hegemon no sistema internacional. Nesse sentido, seria importante a existência de uma potência hegemônica responsável por convergir os diversos interesses individuais e por definir regras para a circulação do capital e do comércio (MARTINS, 2011).

Os marxistas, em geral, buscam as causas de fenômenos históricos nas relações materiais e econômicas e na ordem social. Segundo essa perspectiva, os interesses econômicos organizam o sistema capitalista. A divisão internacional do trabalho, somada às capacidades financeiras e tecnológicas dos Estados, possibilita a configuração de países centrais e de países periféricos (MARTINS, 2011). Países centrais são caracterizados por maior capacidade técnica e maior abundância de capital, e exploram países periféricos, caracterizados por abundância de mão de obra pouco especializada e tecnologia restrita. Há, segundo Celso Furtado, tendência inequívoca, portanto, de deterioração dos termos de troca entre esses dois mundos, com consequências perversas para os países periféricos.

No século XIX, podia-se vincular a Inglaterra como centro e o Brasil como periferia do sistema internacional. A Inglaterra foi um dos primeiros Estados a consolidar-se como tal; foi o primeiro a passar pela Revolução Industrial, que 
$43 \mid$ InterAção

alterou sobremaneira as relações entre capital e trabalho; ao mesmo tempo, defendia o livre comércio e, por isso, o fim da escravidão para gerar aumento do mercado consumidor. O Brasil, por sua vez, foi colônia portuguesa até 1822 e depois passou a se subordinar fortemente à Inglaterra; se consolidou como Estado nacional somente em meados do século XIX; e manteve economia agroexportadora até meados do século XX. A relação de dependência do Brasil em relação à Inglaterra será discutida na próxima seção.

Wallerstein define hegemonia como “breve período de tempo em que uma potência expressa sua superioridade produtiva, comercial e financeira sobre as demais" (MARTINS, 2011, p.53). Houve, segundo Wallerstein, três momentos em que um hegemon dominou o sistema internacional: (i) 1625-1672, Holanda; (ii) 1815-1873, Inglaterra; e (iii) 1945-1968, Estados Unidos da América. Importante ter em mente que todos estes períodos tiveram em comum a ideologia liberal, que propõe a livre circulação dos fatores de produção e, apoiados no liberalismo político, criaram condições domésticas de estabilidade social e política (MARTINS, 2011). Dessa forma,

A hegemonia não pode ser qualificada como um fenômeno estritamente econômico, de liderança produtiva, comercial e financeira. A hegemonia possui também uma dimensão institucional e não pode ser um fenômeno de curta duração. (MARTINS, 2011, p.55).

Por fim, a hegemonia, para os marxistas, possui duas dimensões: liderar o sistema internacional na direção desejada, e envolver os demais Estados do sistema para sua via de desenvolvimento. Assim, "a chave da hegemonia esta justamente na capacidade de estabelecer convergências entre os objetivos particulares, viabilizando a formulação de um interesse global hierarquizado em favor da potência que o articula" (MARTINS, 2011, p.58). 
$44 \mid$ InterAção

No século XIX, a Inglaterra dominava o comércio internacional amparada por sua marinha; dominava as finanças internacionais, por deter a maior reserva metálica durante o período que vigorou o padrão ouro; dominava a produção industrial e, logo, os lucros. A posição incontestável de hegemonia mundial proporcionou à Inglaterra um ciclo vicioso de crescimento baseado na exploração das periferias e na consecução de mercado consumidor por intermédio de práticas imperialistas, e a possibilidade de interferir na política de diversos países, como fica claro na análise da influência britânica no Brasil do século XIX.

\section{A HEGEMONIA BRITÂNICA NO BRASIL DO SÉCULO XIX}

A penetração inglesa marcará o século XIX brasileiro. Predominam os ingleses em nosso mercado: trazendo mercadorias de toda espécie, levam matérias primas, como algodão, e produtos agrícolas ou derivados da pecuária. Investem grandes capitais: em títulos de empréstimos do governo, em companhias mineiras, em estradas de ferro e em inúmeras outras empresas. Influem em todos os aspectos da vida brasileira. (HOLANDA, 2003, p.75).

A relação de dependência de Portugal frente à Inglaterra remonta ao século XVIII, durante a Guerra de Sucessão Espanhola (1702-1714). Nesse conflito, estabeleceram-se alianças que perdurariam durante mais de dois séculos entre Inglaterra e Portugal, de um lado, e entre França e Espanha, do outro lado. Os aliados se enfrentaram militar e diplomaticamente em outros conflitos, como a Guerra dos Sete Anos (1756-1763), e o padrão de amizade e dependência de Portugal em relação à Inglaterra foi herdado pelo Brasil independente.

Durante as guerras Napoleônicas, Portugal foi invadido pela França, o que precipitou a transmigração da Corte lusa para sua colônia mais próspera 
(FAUSTO, 2003; LINHARES, 1990; HOLANDA, 2003). Maria Odila Dias (1972) defende que a vinda da Família Real, em 1808, promoveu a interiorização da metrópole que, enraizada no centro-sul do Brasil, teria acelerado o processo de independência. Essa longa viagem da Europa à América aconteceu sob escolta britânica que, como forma de compensação, foi agraciada com a assinatura do Tratado de Comércio de 1810 que dava à Inglaterra vantagens comerciais àquela potência.

[O] domínio econômico [inglês], começado em Portugal, vinha prolongar-se no Brasil, e pela magnanimidade e profundo reconhecimento lusitano deu origem ao Tratado de Comércio Anglo-Lusitano de 1810, que mandava cobrar 15\% de direitos para as mercadorias transportadas pelo pavilhão inglês, enquanto as próprias importações de Portugal eram oneradas com 16\%. (HOLANDA, 2003, p.116).

O período joanino foi caracterizado pela modernização do estado brasileiro e pela participação assertiva da Inglaterra em praticamente todos os campos da vida nacional: a abertura dos portos, em 1808, favoreceu os britânicos ao dar fim ao exclusivo metropolitano; o Tratado de 1810 proporcionava à Inglaterra vantagens comerciais frente aos demais países, e mesmo à Portugal; os ingleses influíam no padrão de consumo nacional e na política externa brasileira, como pode ser verificado nas sucessivas intervenções no Prata em 1811 e 1816 (HOLLANDA, 2003, p.106-114). A Inglaterra, claramente, envolvia o Brasil em sua via de desenvolvimento, auferindo benefícios econômicos e políticos dessa posição e acumulando custos com o resguardo da segurança da nação recémformada.

Após a Independência, o Brasil inaugura, oficialmente, sua inserção periférica no sistema capitalista dominado pelos ingleses. Os Tratados de Comércio de 1810 foram renovados em 1825, o que provocava crise econômica devido à baixa arrecadação aduaneira do Império. Em 1828, a extensão da tarifa 
46 | InterAção

de $15 \%$ para todos os Estados independentes gera queda vertiginosa na arrecadação e piora a situação econômica do Brasil (FAUSTO, 2003). Como hegemon, a Inglaterra impôs a abertura dos portos, primeiramente a ela e logo, em consonância com sua defesa do livre comércio, a todas as nações amigas, gerenciando o sistema internacional convergente com seus interesses.

Somavam-se às baixas tarifas aduaneiras, os empréstimos feitos por D. Pedro I para comprar o reconhecimento da independência do Brasil de Portugal (FAUSTO, 2003; BETHELL, 2012). No primeiro Reinado, o Brasil adquiriu 2 milhões de libras em Londres para esse fim. "A necessidade de indenizar a Coroa portuguesa deu origem ao primeiro empréstimo externo, contraído pelo Brasil em Londres" (FAUSTO, 2003, p.144). A dependência brasileira deixava de ser apenas comercial e passava a ser também financeira em relação à Inglaterra. Importante mencionar a importância da atuação britânica na mediação do reconhecimento do novo Estado por Portugal (FAUSTO, 2003, p. 143-146), especialmente o papel de George Canning (HOLANDA, 2003, p.379-381).

A dependência financeira em relação à Inglaterra foi reforçada com novos empréstimos vultosos na city londrina para os esforços de guerra do Império na Guerra da Cisplatina (1825-1827), o que gerou aumento significativo do endividamento nacional. Além disso, novamente a mediação inglesa se fez sentir, em 1828, com a independência do Uruguai e a consecução da paz no Prata (HOLANDA, 2012, p.373-374). Importante ter em mente essa relação de complementaridade entre a submissão econômica e a influência política que a Inglaterra exercia sobre o Brasil. Essa relação íntima corrobora argumentos tanto de realistas quanto de marxistas.

A hegemonia britânica continuou como característica da política e da economia brasileira no segundo Reinado. Politicamente, o parlamentarismo brasileiro, mesmo que os meios tenham sido diferentes daqueles do 
$47 \mid$ InterAção

parlamentarismo britânico - no Brasil ocorreu o que se denominou de parlamentarismo às avessas, uma vez que o Imperador nomeava o primeiro ministro que, por sua vez, formava o Ministério e o Parlamento -, foi influenciado por ele. Na economia, a Inglaterra permaneceu hegemônica no campo financeiro até a primeira década de século XX, enquanto os EUA se sobrepunham no campo comercial, especialmente devido ao fato de ser o maior comprador do café brasileiro, principal produto da pauta de exportação nacional a partir dos anos 1830.

O primeiro momento de contestação e de protagonismo da política brasileira frente aos interesses britânicos ocorreu na década de 1840 (CERVO, 2002): o Império não renovou os Tratados desiguais, em 1842, e editou a Tarifa Alves Branco (1844) que dobrava o imposto de importação praticado no Brasil; para produtos com similar nacional, o imposto chegava a 60\%. Como resultado, aumenta a arrecadação do país. Amado Cervo (2002) comenta que esse foi um momento de triunfo do pensamento industrialista no Parlamento e afirma que isso poria fim aos passivos políticos e econômicos de dependência frente à Inglaterra. Nesse sentido, a periferia questiona as políticas e imposições do centro da economia mundial.

A autonomia alfandegária e o aumento das receitas decorrentes da Tarifa Alves Branco possibilitaram ao país alguma estabilização econômica devido ao aumento da arrecadação. Além disso, foi um golpe contra a subordinação à Inglaterra, que já durava algumas décadas. Os recursos serviram, sobretudo, para a retomada do intervencionismo no Prata.

A Inglaterra logo buscou retomar a hegemonia econômica frente ao Brasil com a edição da Bill Aberdeen (1845), que taxava navios negreiros como navios piratas em momento que a Inglaterra adotava postura unilateral e agressiva quanto ao tráfico negreiro. Importante ter em mente que em todos os tratados 
48 InterAção

firmados entre Inglaterra e Portugal e, mais tarde, entre Inglaterra e Brasil, havia promessa de Portugal e Brasil quanto ao fim do tráfico. Por ser a principal potência mundial entre os séculos XVIII e XIX, por ter passado pela Revolução Industrial no fim do século XVIII e por defender o livre comércio, a Inglaterra buscava mercados e o sistema escravista praticado na América Portuguesa era um obstáculo a esse fim. Os tratados foram outra forma de liderar o sistema internacional na direção desejada pela potência hegemônica.

O fato de a Inglaterra agir agressivamente contra os navios brasileiros dificultaria a intervenção imperial no Prata. Para resolver essa questão o Brasil edita a Lei Eusébio de Queiroz (1850) que põe fim ao tráfico de escravos no Brasil e garante a neutralidade britânica nas intervenções brasileiras contra Argentina e Uruguai entre as décadas de 1850 e 1860.

A Inglaterra, todavia, permaneceu hegemônica em relação às finanças brasileiras até o início do século XX. O fato de o segundo Reinado ter sido estável politicamente, diferentemente do que ocorria com as repúblicas americanas, proporcionava à Inglaterra que investisse vastos recursos no Brasil. Especialmente nas décadas de 1850-1860, concomitantemente à Era Mauá, ocorriam investimentos externos diretos britânicos em ferrovias, moinhos e engenhos (BETHELL, 2012).

O endividamento brasileiro em relação à Londres foi crescente durante o século XIX. Seu ápice ocorreu durante a Guerra do Paraguai, quando o Brasil adquiriu volumoso estoque de empréstimos com a Inglaterra para financiar seu esforço de guerra:

[O Brasil] teve enormes perdas humanas e materiais [com a guerra] (só superadas, talvez, pelas do Paraguai), ficou com as finanças públicas profundamente abaladas e se viu obrigado a pedir, em setembro de 1865, um empréstimo de sete milhões de libras ao banco Rothchild. (LINHARES, 1990, p.262). 
49 | InterAção

\section{CONSIDERAÇÕES FINAIS}

Pode-se afirmar que há convergência de ideias entre realistas e marxistas no que diz respeito ao papel de uma potência hegemônica no cenário internacional para organizar o sistema. No entanto, enquanto os realistas expressam o caráter de estabilidade proporcionado pela existência de um hegemon, os marxistas criticam a preponderância do centro em relação à periferia.

No século XIX, a hegemonia britânica era clara e incontestável no cenário mundial e essa disparidade política e econômica frente aos demais Estados proporcionou à Inglaterra que gerisse o sistema internacional e que mantivesse a paz por aproximadamente 100 anos. Em uma abordagem realista, o papel da hegemonia serviu para organizar o sistema e assumir responsabilidade por sua estabilidade. Os custos dessa posição - fossem econômicos, políticos ou militares - parecem ter sido superados pelos benefícios proporcionados por ela.

Partindo-se de uma análise marxista, fica claro que a Inglaterra pode liderar o sistema internacional na direção desejada por ela, ou seja, a manutenção do status quo e de sua posição como centro da economia mundial, e envolver os demais Estados do sistema para sua via de desenvolvimento, por exemplo, por intermédio da difusão do liberalismo e de seu império colonial.

Portugal se aproveitou de aliança histórica com a Inglaterra para se utilizar da hegemonia britânica a seu favor, primeiro para garantir a segurança da 
50 InterAção

transmigração da Corte lusa para o Brasil, e o Brasil, depois, para assegurar empréstimos e investimentos para diversos fins. Por outro lado, o Império do Brasil proporcionava à Inglaterra mercado consumidor para seus produtos e matéria prima, favorecendo o crescimento britânico e mantendo-se em posição periférica no sistema econômico internacional.

Um dos principais argumentos historiográficos sobre a manutenção da ordem social e da unidade do Brasil após a independência relaciona-se a submissão do Império frente à Inglaterra. Ilmar Mattos, em Tempo Saquarema (2004), defende que a submissão ao estrangeiro garantiu a manutenção da ordem social mesmo após a Independência. O argumento é que, anteriormente, os colonos se mantinham como elite interna devido à submissão aos colonizadores portugueses, para quem vendiam produtos primários e de quem compravam manufaturas. Com a Independência, o que ocorre é a substituição da submissão a Portugal para a submissão a Inglaterra, possibilitando a manutenção do status dos colonos.

\section{REFERÊNCIAS}

BETHELL, Leslie. O Brasil no mundo. In: CARVALHO, José Murilo de (Coord.). A construção nacional 1830-1889, vol.2. Rio de Janeiro: Objetiva, 2012. CERVO, Amado; BUENO, Clodoaldo. História da política exterior do Brasil. Brasília: Editora Universidade de Brasília, 2002.

DIAS, Maria Odila. A interiorização da metrópole (1808-1853). In: MOTA, C. G. 1822: dimensões. São Paulo: Perspectiva, 1972.

FAUSTO, Boris. História do Brasil. São Paulo: Editora da Universidade de São Paulo, 2003.

GILPIN, R. Equilibrium and decline. War and change, 1981. 
$51 \mid$ InterAção

HOLANDA, Sérgio Buarque de... [et al.]. O Brasil monárquico, tomo II: o processo de emancipação. Rio de Janeiro, Bertrand Brasil: 2003.

LINHARES, Maria Yedda (Org.). História geral do Brasil. Rio de Janeiro: Elsevier, 1990.

MARTINS, Carlos Eduardo. Globalização, dependência e neoliberalismo na América Latina. Boitempo, 2011.

MATTOS, Ilmar. O tempo saquarema. São Paulo: Editora Hucitec, 2004.

PAULA, João Antônio de. O processo econômico. In: CARVALHO, José Murilo de (Coord.). A construção nacional 1830-1889, vol.2. Rio de Janeiro: Objetiva, 2012.

WALTZ, Kenneth. Teoria das relações internacionais. Lisboa: Gradiva, 2002. 